\title{
Long-term results of a phase II study of hypofractionated proton therapy for prostate cancer: moderate versus extreme hypofractionation
}

Boram Ha ${ }^{1,3}$, Kwan Ho Cho ${ }^{1 *}$, Kang Hyun Lee ${ }^{2}$, Jae Young Joung ${ }^{2}$, Yeon-Joo Kim', Sung Uk Lee ${ }^{1}$, Hyunjung Kim', Yang-Gun Suh', Sung Ho Moon', Young Kyung Lim', Jong Hwi Jeong ${ }^{1}$, Haksoo Kim', Weon Seo Park² and Sun Ho Kim²

\begin{abstract}
Background: We performed a prospective phase II study to compare acute toxicity among five different hypofractionated schedules using proton therapy. This study was an exploratory analysis to investigate the secondary end-point of biochemical failure-free survival (BCFFS) of patients with long-term follow-up.

Methods: Eighty-two patients with T1-3bNOMO prostate cancer who had not received androgen-deprivation therapy were randomized to one of five arms: Arm 1, 60 cobalt gray equivalent (CGE)/20 fractions/5 weeks; Arm 2, 54 CGE/15 fractions/5 weeks; Arm 3, 47 CGE/10 fractions/5 weeks; Arm 4, 35 CGE/5 fractions/2.5 weeks; and Arm 5, 35 CGE/5 fractions/4 weeks. In the current exploratory analysis, these ardms were categorized into the moderate hypofractionated (MHF) group (52 patients in Arms 1-3) and the extreme hypofractionated (EHF) group (30 patients in Arms 4-5).
\end{abstract}

Results: At a median follow-up of 7.5 years (range, 1.3-9.6 years), 7-year BCFFS was 76.2\% for the MHF group and 46.2\% for the EHF group ( $p=0.005$ ). The 7-year BCFFS of the MHF and EHF groups were 90.5 and $57.1 \%$ in the low-risk group $(p=0.154) ; 83.5$ and $42.9 \%$ in the intermediate risk group ( $p=0.018)$; and 41.7 and $40.0 \%$ in the high risk group $(p=0.786)$, respectively. Biochemical failure tended to be a late event with a median time to occurrence of 5 years. Acute $\mathrm{GU}$ toxicities were more common in the MHF than the EHF group ( $85 \mathrm{vs.} 57 \%, p=0.009$ ), but late $\mathrm{Gl}$ and $\mathrm{GU}$ toxicities did not differ between groups.

Conclusions: Our results suggest that the efficacy of EHF is potentially inferior to that of MHF and that further studies are warranted, therefore, to confirm these findings.

Trial registration: This study is registered at ClinicalTrials.gov, no. NCT01709253; registered October 18, 2012; retrospectively registered).

Keywords: Dose hypofractionation, Treatment outcome, Prostatic neoplasms, Proton therapy, Radiotherapy

\footnotetext{
* Correspondence: kwancho@ncc.re.kr

${ }^{1}$ Proton Therapy Center, National Cancer Center, 323 Ilsan-ro, Ilsandong-gu,

Goyang-si, Gyeonggi-do 10408, Republic of Korea

Full list of author information is available at the end of the article
}

(c) The Author(s). 2019 Open Access This article is distributed under the terms of the Creative Commons Attribution 4.0 International License (http://creativecommons.org/licenses/by/4.0/), which permits unrestricted use, distribution, and reproduction in any medium, provided you give appropriate credit to the original author(s) and the source, provide a link to the Creative Commons license, and indicate if changes were made. The Creative Commons Public Domain Dedication waiver (http://creativecommons.org/publicdomain/zero/1.0/) applies to the data made available in this article, unless otherwise stated. 


\section{Background}

The $\alpha / \beta$ ratio for prostate cancer is known to be very low (range, $0.9-2.2 \mathrm{~Gy}$ ) [1-5]. A lower $\alpha / \beta$ ratio than that of the surrounding normal tissue has suggested that hypofractionated schedules might increase the therapeutic ratio. We have previously reported the interim results of phase II trial comparing five different hypofractionation dose schedules using proton beam therapy (PBT) [6]. Because of its unique dose-distribution, PBT is better for delivering highly conformal radiation to the prostate while sparing the adjacent rectum and bladder [7], and is considered an effective method to deliver high doses per fraction, although there is no clear evidence that PBT offers a clinical advantage over any other form of definitive radiotherapy. As comparative studies on the efficacy of different hypofractionation dose schedules are lacking, we conducted an exploratory analysis of the phase II trial comparing outcomes between moderate hypofractionation (MHF; fractional dose < 5 Gy) and extreme hypofractionation (EHF; fractional dose $\geq 5 \mathrm{~Gy}$ ).

\section{Methods}

\section{Study design and patient eligibility}

This was an exploratory single institution phase II trial comparing five different hypofractionated schedules in males with localized prostate cancer. Patients with biopsy-proven androgen-deprivation therapy (ADT)naive prostate adenocarcinoma, stage T1-3NOM0 and an Eastern Cooperative Oncology Group performance status of $0-2$ were eligible for the trial. Patients were randomly assigned to five different dose schedules using block randomization method. Our institutional review board approved the study protocol. For staging, abdomen and pelvic computerized tomography $(\mathrm{CT})$, prostate magnetic resonance imaging (MRI), and whole-body bone scans were performed in all patients. Positron-emitting tomography (PET)/CT was not routinely performed. Table 1 lists each hypofractionated schedule and equivalent dose using 2 Gy (EQD2) in five arms. The rationale for the dose/fractionation schedule was described in our previous report [6]. Briefly, assuming an $\alpha / \beta$ ratio of $1.5 \mathrm{~Gy}$ for prostate cancer and $3 \mathrm{~Gy}$ for normal tissue late toxicities, five hypofractionated schedules with the same biologically equivalent dose of $72 \mathrm{~Gy}$ in $2 \mathrm{~Gy}$ fractions for a late effect were chosen. Each schedule was adjusted to be delivered $<5$ times per week (1-4 times per week) to reduce the acute rectal mucosal toxicity. The effect of repopulation for prostate cancer during treatment was not considered [8].

\section{PBT}

Details of the simulation and treatment planning for PBT at our institution have been previously reported $[6,9]$. Briefly, three gold markers were inserted into the prostate and used to verify the exact location of the prostate for each treatment session. A balloon was inserted into the rectum and filled with $100 \mathrm{~mL}$ saline for both CT and MRI scans to guide treatment planning. A set of 3-mm-thick contrast CT images and MRI scans was acquired on the same day. The CT and MRI images were fused using a registration algorithm and targets were delineated on the fused images. The clinical target volume (CTV) was defined as the whole prostate plus the proximal $1 \mathrm{~cm}$ of seminal vesicles, or whole seminal vesicles in cases of involvement. We did not treat seminal vesicles or regional lymph nodes electively when using hypofractionation due to toxicity concerns. The planning target volume (PTV) was created by adding $1.0 \mathrm{~cm}$ to the CTV in all directions except posteriorly, where $0.7 \mathrm{~cm}$ was added. The treatments were planned using an Eclipse proton beam planning system (Varian Medical Systems, Palo Alto, CA, USA). An opposing pair of bilateral beams was used and the dose was projected to the $100 \%$ isodose line. The plan was normalized so that $95 \%$ of the PTV received the

Table 1 Five hypofractionated schedules and equivalent dose in 2-Gy

\begin{tabular}{|c|c|c|c|c|c|c|c|c|}
\hline & & \multirow[b]{2}{*}{$\begin{array}{l}\text { Daily dose } \\
\text { (CGE) }\end{array}$} & \multirow[b]{2}{*}{$\begin{array}{l}\text { Number of } \\
\text { fractions }\end{array}$} & \multirow[b]{2}{*}{ fractions / week } & \multirow[b]{2}{*}{$\begin{array}{l}\text { Treatment } \\
\text { time (Days) }\end{array}$} & \multicolumn{3}{|l|}{ EQD2 } \\
\hline & & & & & & $\begin{array}{l}\text { Prostate cancer } \\
(\alpha / \beta=1.5 \mathrm{~Gy})\end{array}$ & $\begin{array}{l}\text { Acute toxicity } \\
(\alpha / \beta=10 \mathrm{~Gy})\end{array}$ & $\begin{array}{l}\text { Late toxicity } \\
(\alpha / \beta=3 \mathrm{~Gy})\end{array}$ \\
\hline \multicolumn{2}{|c|}{ Reference dose in $2 \mathrm{~Gy} /$ fraction } & 2 & 36 & 5 & 49 & 72.0 & 72.0 & 72.0 \\
\hline \multirow[t]{3}{*}{ MHF } & Arm 1 & 3 & 20 & $\begin{array}{l}4 \\
\text { (Mon. Tue, Thu, Fri) }\end{array}$ & 32 & 77.1 & 69.6 & 72.0 \\
\hline & Arm 2 & 3.6 & 15 & $\begin{array}{l}3 \\
\text { (Mon, Wed, Fri) }\end{array}$ & 32 & 78.7 & 63.8 & 71.3 \\
\hline & Arm 3 & 4.7 & 10 & $\begin{array}{l}2 \\
\text { (Tue, Thu) }\end{array}$ & 30 & 83.3 & 58.2 & 72.4 \\
\hline \multirow[t]{2}{*}{ EHF } & Arm 4 & 7 & 5 & $\begin{array}{l}2 \\
\text { (Tue, Thu) }\end{array}$ & 14 & 85.0 & 55.5 & 70.0 \\
\hline & Arm 5 & 7 & 5 & $\begin{array}{l}1 \\
\text { (Wed) }\end{array}$ & 28 & 85.0 & 46.3 & 70.0 \\
\hline
\end{tabular}


prescribed dose. The dose-volume constraints for the organs at risk involved a volume receiving 50 Gy EQD2, which should not have exceeded 30\% for the rectum and bladder. During every treatment session, digital orthogonal $\mathrm{x}$-ray images were acquired and transferred to the digital image positioning system. The three-dimensional relative locations of the gold markers in the digital images were then compared with those in the reference images. Any differences between the two images were calculated automatically by the system and the treatment couch was adjusted to eliminate any discrepancies greater than $1 \mathrm{~mm}$.

\section{ADT}

Multimodal therapy consisting of radiation and ADT is the current standard of care for high-risk patients. In this study, 17 high-risk patients who had refused ADT or were unfit for ADT due to other medical co-morbidities such as a history of coronary arterial or cerebro-vascular disease, were included and treated with PBT alone. ADT was allowed as a salvage treatment in cases of biochemical or clinical failure during follow-up.

\section{Statistical analysis}

The primary objective was to compare the acute toxicities and determine the best arm with the lowest toxicities, and the secondary objectives were to compare the biochemical failure-free survival (BCFFS), overall survival (OS), and long-term toxicities [6]. Severe acute toxicity was defined as grade $\geq 2$ toxicity. With a $90 \%$ probability of selecting the best arm with a $30 \%$ difference between the best arm and the other four arms in terms of severe acute toxicity, 18 patients were needed per arm. Assuming a follow-up loss of 5\%, 19 patients were needed per arm [10]. Thus, a total of 95 patients were scheduled for enrollment. However, because the interim analyses revealed a higher biochemical failure (BCF) in Arm 5 (35 Gy/5 fractions/once per week for 4 weeks), an accrual to Arm 5 was terminated after the enrollment of 12 patients. Survival was estimated using the Kaplan-Meier method and compared using the log-rank test. A Cox regression hazard model was used for multivariate analysis and significance was determined at $p<0.05$. Toxicity events were compared using the chi-square and Fisher's exact tests.

\section{Data collection and follow-up}

BCF was defined as an increase in serum prostate specific antigen (PSA) $>2.0 \mathrm{ng} / \mathrm{mL}$ from the nadir according to the Phoenix definition (RTOG-ASTRO Phoenix Consensus Conference 2006). Acute gastrointestinal (GI) and genitourinary (GU) toxicities were rated according to the National Cancer Institute Common Toxicity Criteria (https:// ctep.cancer.gov/protocolDevelopment/electronic_appli cations/docs/ctcaev3.pdf) and were assessed weekly during and 1 month after completion of the PBT. Patients were followed every 3 months during the first 2 years, every 6 months during the next 3 years, and annually thereafter. The late GI and GU toxicities were evaluated using the RTOG/European Organization for Research and Treatment of Cancer late radiation morbidity scoring system. The risk groups were divided according to the National Comprehensive Cancer Network Practice Guideline (NCCN V2 2009).

\section{Results}

\section{Study population}

We defined MHF as a fractional dose < 5 Gy per fraction and EHF as a fractional dose $>5$ Gy. Of a total of $82 \mathrm{pa}-$ tients, 52 patients were treated with MHF (19 in Arm 1, 16 in Arm 2, and 17 in Arm 3) and 30 were with EHF (18 in Arm 4 and 12 in Arm 5). The baseline patient and tumor characteristics are summarized in Table 2 . The median age of the entire study population was 68 years (range, 44-85 years). The majority of patients had Gleason score 6 disease (63\%), a PSA $<10 \mathrm{ng} / \mathrm{mL}(67 \%)$, and T1 (35\%) or T2 disease (54\%). Most of the patients had low (34\%) or intermediate (45\%) risk disease and $21 \%$ had high risk disease.

\section{BCFFS and OS}

At a median follow-up of 7.5 years (range, 1.3-9.6 years), 35 patients had BCF with 15 in the MHF group and 20 in the EHF group. Among the 15 patients with BCF in the MHF group, three patients eventually developed local recurrences and one patient developed distant metastasis. In the EHF group, there were two local recurrences and one distant metastasis among the 20 patients with BCF.

The median time to onset of BCF was 5.0 years (range, 1.4-9.1 years). Figure 1 shows the Kaplan-Meier survival curves for the BCFFS in the original five different dose schedules (a) and the MHF and EHF groups (b). A steep decline in the BCFFS in the EHF group was observed after 4 years, which resulted in a significantly lower 7-year BCFFS in the EHF group (46.2 vs. $76.2 \%$; $p=0.005$ ). Using multivariable analyses, the hazard ratio was 3.24 for the EHF group (95\% confidence interval, 1.51-6.93, $p=0.003$ ), after adjusting for age, Gleason score, pretreatment PSA, and $\mathrm{T}$ stage. The 7-year BCFFS in the MHF and EHF groups were 90.5 and $57.1 \%$ for the low risk group $(p=0.154), 83.5$ and $42.9 \%$ for the intermediate risk group $(p=0.018)$, and 41.7 and $40.0 \%$ for the high risk group, respectively ( $p=0.786$ ) (Fig. 2).

Among the three deaths at the time of analysis, only one was caused by progression of bone metastases from the prostate cancer; the others were caused by other malignancies, including lung cancer and leukemia. The 7-year OS was $97.5 \%$ for the entire study population. The OS was not compared between the two groups because of the low frequency of events. 
Table 2 Patients' characteristics

\begin{tabular}{|c|c|c|c|c|}
\hline Characteristics & MFH $(n=52)$ & $\operatorname{EHF}(n=30)$ & $P$ & Total $(n=82)$ \\
\hline Age, median (range) & $68(44-85)$ & $68(46-80)$ & .464 & $68(44-85)$ \\
\hline \multicolumn{5}{|l|}{ ECOG PS } \\
\hline 0 & 10 (19\%) & $10(33 \%)$ & $.249^{\mathrm{a})}$ & $20(24 \%)$ \\
\hline 1 & $41(79 \%)$ & $20(67 \%)$ & & $61(75 \%)$ \\
\hline 2 & $1(2 \%)$ & 0 & & $1(1 \%)$ \\
\hline \multicolumn{5}{|l|}{ Gleason score } \\
\hline$\leq 6$ & $35(67 \%)$ & $17(57 \%)$ & $.544^{\mathrm{a})}$ & $52(63 \%)$ \\
\hline 7 & $14(27 \%)$ & $10(33 \%)$ & & $24(29 \%)$ \\
\hline $8-10$ & $3(6 \%)$ & $3(10 \%)$ & & $6(7 \%)$ \\
\hline \multicolumn{5}{|l|}{ Initial PSA (ng/ml) } \\
\hline$<10$ & $36(69 \%)$ & $19(63 \%)$ & $.203^{\mathrm{a})}$ & $55(67 \%)$ \\
\hline $10-20$ & $12(23 \%)$ & $11(37 \%)$ & & $23(28 \%)$ \\
\hline$>20$ & $4(8 \%)$ & $0(0 \%)$ & & $4(5 \%)$ \\
\hline \multicolumn{5}{|l|}{ T stage } \\
\hline $\mathrm{T} 1$ & $20(38 \%)$ & $9(30 \%)$ & $.362^{b)}$ & $29(35 \%)$ \\
\hline $\mathrm{T} 2$ & $25(48 \%)$ & $19(63 \%)$ & & $44(54 \%)$ \\
\hline T3 & $7(13 \%)$ & $2(7 \%)$ & & $9(11 \%)$ \\
\hline \multicolumn{5}{|l|}{ NCCN Risk group } \\
\hline Low & $21(40 \%)$ & $7(23 \%)$ & $.131^{b)}$ & $28(34 \%)$ \\
\hline Intermediate & $19(37 \%)$ & $18(60 \%)$ & & $37(45 \%)$ \\
\hline High & $12(23 \%)$ & $5(17 \%)$ & & 17 (21\%) \\
\hline
\end{tabular}

$M H F$ moderate hypofractionation, EHF extreme hypofractionation, ECOG Eastern Cooperative Oncology Group, PS performance status, NCCN National Comprehensive Cancer Network V2 2009

${ }^{a)}$ Fisher's exact test; ${ }^{\text {b) }}$ Chi-square test

\section{Acute and late $\mathrm{GI}$ and $\mathrm{GU}$ toxicities}

Table 3 summarizes the acute and late toxicities. No significant differences were observed in the overall incidences of acute and late toxicities. Grade 2 or higher acute GI toxicities were not observed. The incidences of grade 1 and 2 acute $\mathrm{GU}$ toxicities were 81 and $4 \%$ in the MHF group and 50 and $7 \%$ in the EHF group, respectively ( $p=0.009$ ), and grade 3 acute $\mathrm{GU}$ toxicity was not observed in either group. Grade 2 and 3 late GI toxicities were observed in eight (15\%) and two (4\%) patients in the MHF group and four (13\%) and zero patients in the EHF group $(p=0.891)$. Grade 2 late GU toxicities were observed in six (12\%) and two (7\%) patients in the MHF and EHF groups, respectively $(p=0.835)$.

\section{Discussion}

To our knowledge, this is the first prospective study to compare the efficacy of EHF and MHF in patients with prostate cancer. In our exploratory analyses, the 7-year BCFFS rates of the MHF and EHF groups were 76 and $46 \%$, respectively, for all patients $(p=0.005)$. The effect of the fractionation schedule was statistically significant for the intermediate risk group ( 84 vs. $43 \%$, respectively; $p=0.018$, but not for the low or high risk group. For the low risk group, the difference in the 7-year BCFFS was substantial (91 vs. $57 \%, p=0.154$ ), but did not reach significance because of the small sample size $(n=28$ patients). For the high risk group, the 7-year BCFFS was suboptimal regardless of the fractionation scheme in which the ADT should have been added to the radiotherapy as standard care. The BCF tended to be a late event with a median time to occurrence of 60.0 months. As shown in Fig. 1, there was a steep decline in the BCFFS in the EHF group between the 4th and 5th years, which further suggested that a long-term follow-up was needed.

There are several possible explanations why the BCFFS of EHF was inferior to that of MHF. The two assumptions in this study were that the $\alpha / \beta$ ratio was $1.5 \mathrm{~Gy}$ and that repopulation was negligible during treatment. Assuming an $\alpha / \beta$ ratio of $1.5 \mathrm{~Gy}$, the EQD2 for the EHF group was $85 \mathrm{~Gy}$, which was greater than the 77.1-83.3 Gy of the MHF group (Table 1), but the actual outcomes were worse in the EHF group, which was contrary to our expectation. Although most of the evidence supports a very low $\alpha / \beta$ value for prostate cancer involving < 2.0 Gy [1-4], there have been a few studies supporting higher values. Miralbell et al. [5] reported that the $\alpha / \beta$ ratio could be increased from $1.5 \mathrm{~Gy}$ to $4 \mathrm{~Gy}$ when the overall treatment time is longer than the lag period for accelerated repopulation. Williams et al. [11] examined the effects of fraction size and total dose of radiotherapy in 3756 patients treated with radiation alone at three institutions, and estimated an $\alpha / \beta$ ratio of $3.7 \mathrm{~Gy}$. Nahum et al. [12] reported $\alpha / \beta$ ratios of $8.5 \mathrm{~Gy}$ and $15.5 \mathrm{~Gy}$, when considering the heterogeneity of prostate cancer and hypoxia.

In a review of comparative randomized trials, Pollack et al. [13] reported the results of a trial comparing hypofractionation (HF) (70.2 Gy/26 fractions) with conventional fractionation (CF) (76 Gy/36 fractions). Assuming an $\alpha / \beta$ ratio of $1.5 \mathrm{~Gy}$, the EQD2 for $\mathrm{HF}$ of $84.4 \mathrm{~Gy}$ would significantly reduce the biochemical/clinical disease failure (BCDF), but there was no significant difference in the BCDF between the treatment arms (23.3 vs. $21.4 \%$ at 5 years, respectively; $p=0.268$ ). In the RTOG 0415 trial [14], 1092 men with low risk prostate cancer were randomly assigned to CF (73.8 Gy/41 fractions/8.2 weeks) or HF (70 Gy/28 fractions/5.6 weeks). The 5-year disease-free survival was 85.3 vs. $86.3 \%$, respectively, so it was concluded that the efficacy of the $70 \mathrm{~Gy} / 28 \mathrm{frac}$ tions was not inferior to the $73.8 \mathrm{~Gy} / 41$ fractions. Incrocci et al. [15] reported the results of a randomized trial (HYPRO) comparing a HF of $64.6 \mathrm{~Gy} / 19$ fractions with a CF of $78.0 \mathrm{~Gy} / 39$ fractions in patients with intermediate and high risk prostate cancers. Based on an $\alpha / \beta$ ratio of $1.5 \mathrm{~Gy}$, the EQD2 was $90.4 \mathrm{~Gy}$ for the HF compared with $78.0 \mathrm{~Gy}$ for the CF. Two-thirds of the patients also received concomitant ADT for 32 months. 

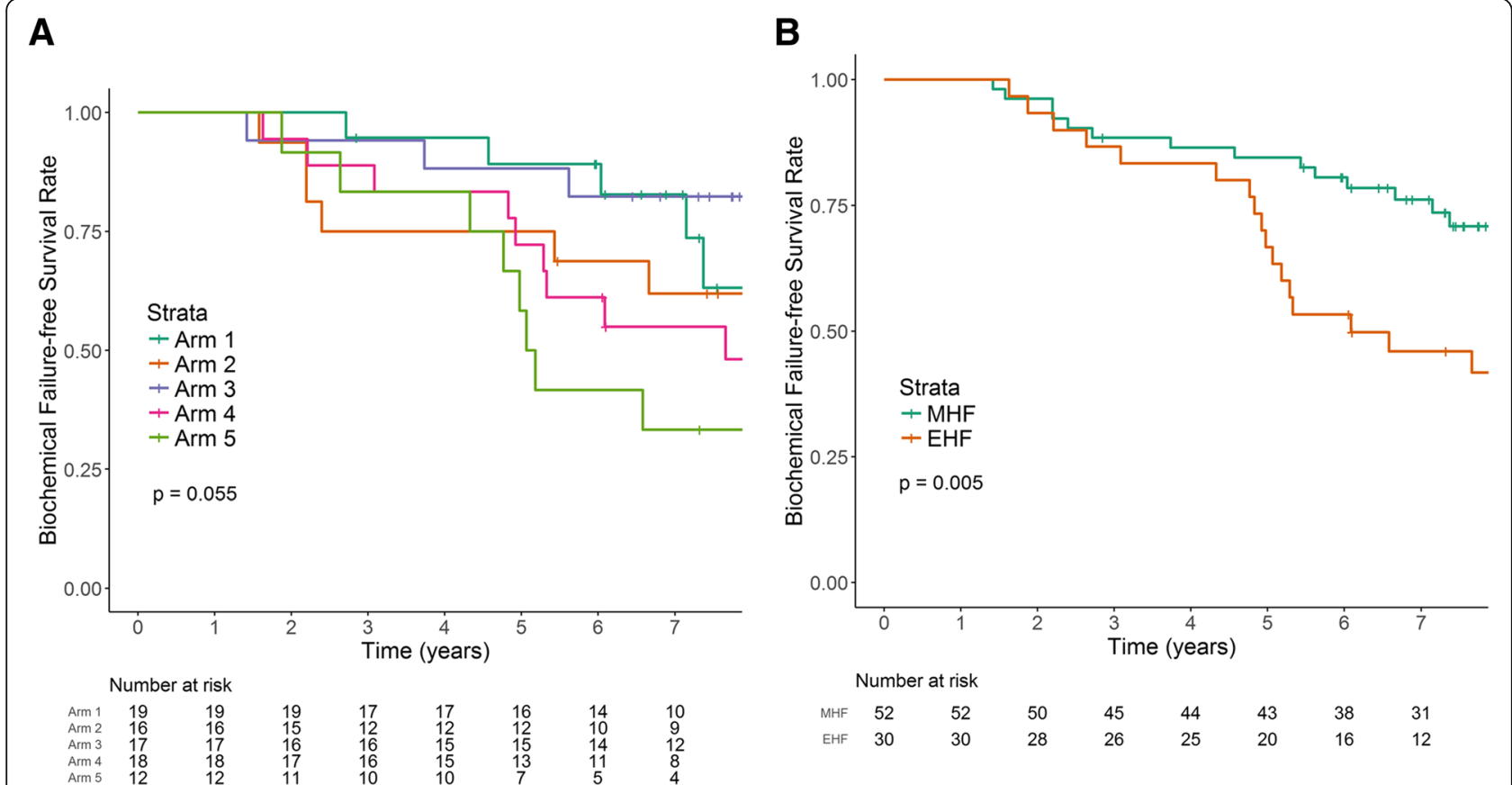

Fig. 1 a Estimated biochemical failure-free survival (BCFFS) of the original five different dose schedules. $\mathbf{b}$ Estimated BCFFS after separation into the moderate hypofractionation (MHF) group with a fractional dose $<5 \mathrm{~Gy}$ and extreme hypofractionation (EHF) group with a fractional dose $\geq 5$ Gy

With a median follow-up of 60 months, the 5-year relapse-free survival was 80.5 vs. $77.1 \%$, respectively $(p=0.36)$. The CHHiP trial [16] was a phase III non-inferiority trial involving patients with localized prostate cancer who were randomly assigned (1:1:1) to the CF arm (74 Gy/37 fractions/7.4 weeks) or to one of two HF arms $(60 \mathrm{~Gy} / 20$ fractions/4 weeks or $57 \mathrm{~Gy} / 19$ fractions/3.8 weeks). Most patients were treated with radiotherapy with 3-6 months of neoadjuvant and concurrent ADT. With a median follow-up of 62.4 months, the BCDF at 5 years was
$88.3 \%$ in the 74 Gy group, $90.6 \%$ in the 60 Gy group, and $85.9 \%$ in the $57 \mathrm{~Gy}$ group. The $60 \mathrm{~Gy}$ group was non-inferior to the $74 \mathrm{~Gy}$ group but there was no non-inferiority for the 57 Gy group compared with the 74.Gy group. In the PROFIT trial [17], more than 1200 intermediate risk patients were randomly allocated to a CF of $78 \mathrm{~Gy} / 39$ fractions/8 weeks or to a HF of $60 \mathrm{~Gy} / 20$ fractions/4 weeks. ADT was not permitted. With a median follow-up of 6.0 years, the 5 -year BCFFS was $85 \%$ in both arms. All of these studies reported that the $\alpha / \beta$ ratio of prostate cancer

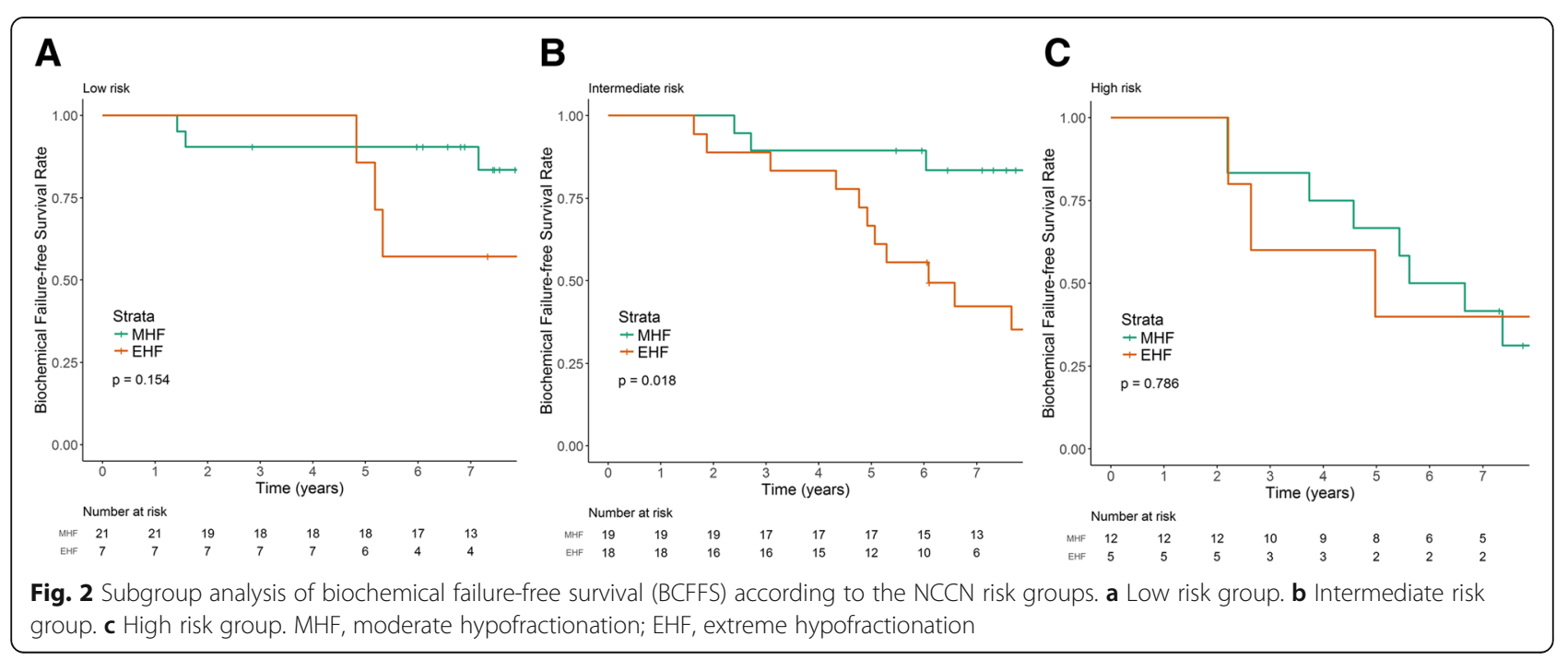


Table 3 Maximum acute and late Gl and GU toxicity

\begin{tabular}{|c|c|c|c|c|}
\hline Maximum grade & MHF $(n=52)$ & $\operatorname{EHF}(n=30)$ & $P$ & Total $(n=82)$ \\
\hline \multicolumn{5}{|l|}{ Acute toxicity } \\
\hline \multicolumn{5}{|l|}{$\mathrm{Gl}$} \\
\hline 0 & 46 (89\%) & $24(80 \%)$ & $.341^{\mathrm{b})}$ & 70 (85\%) \\
\hline 1 & $6(11 \%)$ & $6(20 \%)$ & & $12(15 \%)$ \\
\hline \multicolumn{5}{|l|}{ GU } \\
\hline 0 & $8(15 \%)$ & $13(43 \%)$ & $.009^{b)}$ & $21(26 \%)$ \\
\hline 1 & 42 (81\%) & $15(50 \%)$ & & 57 (70\%) \\
\hline 2 & $2(4 \%)$ & $2(7 \%)$ & & $4(5 \%)$ \\
\hline \multicolumn{5}{|l|}{ Late toxicity } \\
\hline \multicolumn{5}{|l|}{ Gl } \\
\hline 0 & $15(29 \%)$ & $10(33 \%)$ & $.891^{\mathrm{b})}$ & $25(31 \%)$ \\
\hline 1 & 27 (52\%) & 16 (53\%) & & 43 (52\%) \\
\hline 2 & $8(15 \%)$ & $4(13 \%)$ & & 12 (15\%) \\
\hline 3 & $2(4 \%)$ & $0(0 \%)$ & & $2(2 \%)$ \\
\hline \multicolumn{5}{|l|}{$G U^{a)}$} \\
\hline 0 & 32 (62\%) & 19 (63\%) & $.835^{\mathrm{a})}$ & $51(62 \%)$ \\
\hline 1 & $14(27 \%)$ & $9(30 \%)$ & & $23(28 \%)$ \\
\hline 2 & $6(12 \%)$ & $2(7 \%)$ & & $8(10 \%)$ \\
\hline
\end{tabular}

$\overline{M H F}$ moderate hypofractionation, EHF extreme hypofractionation, Gl gastrointestinal, GU genitourinary

${ }^{\text {a) }}$ Chi-square test

${ }^{b}$ Fisher's exact test

was low, but there was considerable uncertainty concerning the estimated value. Table 4 summarizes the treatment outcomes of the MHF and EHF trials with an estimated EQD2. We showed EQD2 assuming an $\alpha / \beta$ ratio of $1.5 \mathrm{~Gy}$, as well as $3-4 \mathrm{~Gy}$ for comparison. Interestingly, the outcomes between the CF and HF in these trials could be better explained with a higher $\alpha / \beta$ ratio of 3 or $4 \mathrm{~Gy}$ for the first four trials [13-16] except for the PROFIT trial [17]. Likewise, for the present study, assuming an $\alpha / \beta$ ratio of $3-4$ Gy better fitted for the outcomes which were worse among the EHF group. The EQD2s for the EHF group were greater than those for the MHF group when an $\alpha / \beta$ ratio of $1.5 \mathrm{~Gy}$ was assumed ( $85 \mathrm{~Gy}$ vs. $77.1-83.3 \mathrm{~Gy}$ ). Assuming an $\alpha / \beta$ ratio of $4 \mathrm{~Gy}$, the EQD2s for each schedule were $70.0,68.4,68.2,64.2$, and $64.2 \mathrm{~Gy}$, respectively (Table 4).

Several single-arm EHF trials using stereotactic body radiotherapy (SBRT) for prostate cancer [18-22] have been conducted to date. The largest series with the longest follow-up [22] involved 515 patients treated with 35-36.25 Gy/5 fractions using SBRT. At a median follow-up of 72 months, the 7-year BCFFSs were 95.8, 89.3 , and $68.5 \%$ for the low-, intermediate-, and high-risk groups, respectively. In a pooled analysis of 1100 patients from eight centers, King et al. [19] reported 5-year BCFFSs of 95.8, 89.3, and 68.5\%, respectively, with a median follow-up of 36 months. The corresponding values determined in our study were 57.1, 42.9 , and $40.0 \%$ at 7 years, despite a very similar dose fractionation scheme ( $35 \mathrm{~Gy} / 5$ fractions). The superior outcome of the former studies could be attributed to the administration of ADT; 8, 16.3, and 55.3\% for the low, intermediate, and high risk groups, respectively, in one study [22], and 8, 15, and 38\%, respectively, in the other [19]. In our study, ADT was not administered unless there was BCF during follow-up. Additionally, our study had the longest follow-up with a median of 90 months, which could be attributed to the lower BCFFS rates, because $B C F$ is a late event with a median time to failure of 60 months, which could have been even longer when ADT was administered in the former studies.

Time/dose/fractionation schemes might also have been responsible for the discrepancies in the outcomes. The only noticeable difference in the time/dose/fractionation was the frequency of treatment. In previous studies, treatments were administered daily or every other day with an overall treatment time (OTT) per 1.0-1.5 weeks. In our study, patients were treated twice a week (Arm 4) or weekly (Arm 5) with an OTT of 2-4 weeks. Tumor cell repopulation in prostate cancer has been considered negligible when the OTT is no longer than 9-10 weeks [8]. A recent study [23] estimated the tumor repopulation rate and its onset time from previous reports of prostate cancer $[8,24,25]$ based on a linear quadratic model and suggested an onset time of 34 days and not longer than 58 days. A few studies [26-28] have reported a detrimental effect of prolonged OTT in a CF scheme. In a study of 1796 patients with low risk prostate cancer treated with radiotherapy alone, D’Ambrosio et al. [28] reported that prolonged OTT due to treatment breaks was an adverse factor for the BCF. In another study by Thames et al. [26], a multi-institutional retrospective analysis of 4839 patients with low and intermediate risk disease, the OTT and dose were significant predictors of BCFFS, in which OTT was significant in patients treated with $\geq 70 \mathrm{~Gy}$. However, there was no evidence that an OTT of 2.0-4.0 weeks ( $<35$ days) negatively affected outcomes when compared with an ultra-short OTT of 1.0-1.5 weeks. An ongoing phase II trial of prostate SBRT called PATRIOT (NCT01423474) which compared 40 Gy/ 5 fractions delivered every other day over 11 days vs. once per week over 29 days is expected to clarify this issue.

Acute GU toxicities were more common in the MHF than the EHF group (85\% vs. 57\%, $p=0.009$ ), but late GI and GU toxicities were not different between the groups. These findings were consistent with EQD2 estimates for acute response $(\alpha / \beta=10 \mathrm{~Gy})$ and late response $(\alpha / \beta=3$ Gy) in the normal tissue (Table 1).

The strength of the present study includes a long-term median follow-up of 90 months, which showed a split of 


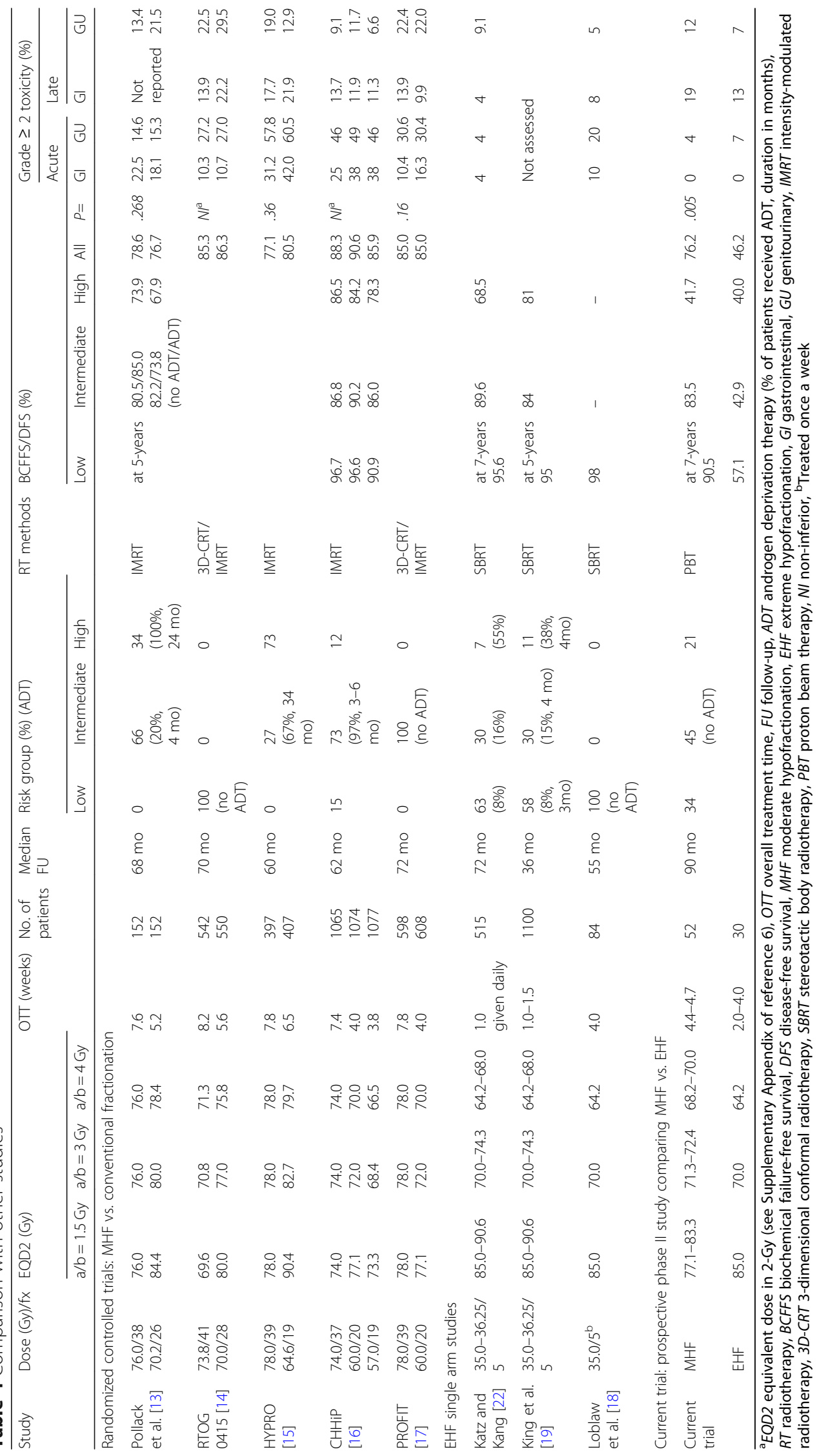


the survival curve after 4 years. A shorter follow-up would not have detected this discrepancy. Additionally, strict eligibility criteria of the ADT-naive patients revealed the sole effect of the fractionation scheme excluding confounding effects due to ADT.

A limitation of this study is that it was an exploratory analysis with a small sample size, which was originally intended to compare acute toxicity among five different dose schedules. The criteria for dividing these five groups into MHF and EHF groups were therefore somewhat arbitrary, although the same subdivision was recently described as "moderate hypofractionation" and "ultrahypofractionation" [29]. In addition, the risk groups were not evenly distributed between the MHF and EHF groups. There were more intermediate-risk patients in the EHF group and more low- and high-risk patients in the MHF group. To overcome this limitation, we compared BCFFS between the two groups according to the risk groups (Fig. 2) and found a statistically significant difference in the intermediate-risk group despite a small sample size $(p=0.018)$. Although our data showed a substantial difference in the efficacy of different hypofractionation schemes in favor of MHF, the result should be interpreted with caution because it is based on an exploratory analysis with a small sample size; our findings should therefore be confirmed in a larger scaled prospective trial. Treating patients with high-risk disease with PBT alone was suboptimal for the current standard of care, with a 7-year BCFFS of approximately $40 \%$ in both the MHF and EHF groups. We did not treat seminal vesicles or regional lymph nodes electively due to toxicity concerns when using hypofractionation. However, we recommend androgen deprivation therapy immediately after the occurrence of biochemical failure. Overall survival at 7 years was $97.5 \%$ for all patients with a very low disease-specific mortality of $1.2 \%$ at 7 years. Only one among the three deaths was related to the progression of bone metastases from prostate cancer.

\section{Conclusion}

Although we are not able to draw a definitive conclusion from the current exploratory analysis, the efficacy of EHF is potentially inferior to MHF; further studies are therefore warranted to confirm these findings. This study is hypothesis-generating; therefore, radiobiological models must be better understood to design a dose/fractionation study. The comparative efficacy of MFH vs. EHF can only be determined by well-designed phase 3 randomized trials comparing "apples with apples".

\section{Abbreviations}

ADT: Androgen-deprivation therapy; BCDF: Biochemical/clinical disease failure; BCF: Biochemical failure; BCFFS: Biochemical failure-free survival; CF: Conventional fractionation; CTV: Clinical target volume; EHF: Extreme hypofractionation; EQD2: Equivalent dose using 2 Gy; Gl: Gastrointestinal; GU: Genitourinary; HF: Hypofractionation; MHF: Moderate hypofractionation; OS: Overall survival; OTT: Overall treatment time; PBT: Proton beam therapy; PTV: Planning target volume; SBRT: Stereotactic body radiotherapy

\section{Acknowledgements}

Not applicable.

\section{Funding}

This work was supported by a National Cancer Center Grant (NCC-1010480, NCC-1310080, NCC-1610590, and NCC-1710060).

\section{Availability of data and materials}

The datasets used and/or analyzed during the current study are available from the corresponding author on reasonable request.

\section{Authors' contributions}

$\mathrm{BH}$ analyzed and interpreted the patient data and a major contributor in writing the manuscript. YJK, SUL, HK, KHL, JYJ, YGS, SHM, YKL, JHJ, and HK also analyzed and interpreted the patient data. WSP and SHK performed the histological and radiological examinations, respectively. $\mathrm{KHC}$ as a corresponding author, supervised all the analysis and edited the manuscript. All authors read and approved the final manuscript.

\section{Ethics approval and consent to participate}

The study protocol was approved by our institutional review board. Written informed consents were obtained from all participants.

\section{Consent for publication}

Not applicable.

Competing interests

The authors declare that they have no competing interests.

\section{Publisher's Note}

Springer Nature remains neutral with regard to jurisdictional claims in published maps and institutional affiliations.

\section{Author details}

${ }^{1}$ Proton Therapy Center, National Cancer Center, 323 Ilsan-ro, Ilsandong-gu, Goyang-si, Gyeonggi-do 10408, Republic of Korea. ${ }^{2}$ Center for Prostate Cancer, National Cancer Center, 323 IIsan-ro, Ilsandong-gu, Goyang-si, Gyeonggi-do 10408, Republic of Korea. ${ }^{3}$ Department of Radiation Oncology, Hallym University Dongtan Sacred Heart Hospital, Seoku-dong, Hwaseong-si, Gyeonggi-do 18450, Republic of Korea.

Received: 6 November 2018 Accepted: 2 January 2019

Published online: 10 January 2019

References

1. Brenner DJ, Hall EJ. Fractionation and protraction for radiotherapy of prostate carcinoma. Int J Radiat Oncol Biol Phys. 1999;43(5):1095-101.

2. Proust-Lima $C$, Taylor JMG, Sécher $S$, et al. Confirmation of a low a/ $\beta$ ratio for prostate cancer treated by external beam radiation therapy alone using a post-treatment repeated-measures model for PSA dynamics. Int J Radiat Oncol Biol Phys. 2011;79(1):195-201.

3. Fowler J, Chappell R, Ritter M. Is alpha/beta for prostate tumors really low? Int J Radiat Oncol Biol Phys. 2001;50(4):1021-31.

4. Dasu A, Toma-Dasu I. Prostate alpha/beta revisited -- an analysis of clinical results from 14168 patients. Acta Oncol. 2012;51(8):963-74.

5. Miralbell R, Roberts SA, Zubizarreta $E$, et al. Dose-fractionation sensitivity of prostate cancer deduced from radiotherapy outcomes of 5,969 patients in seven international institutional datasets: $\alpha / \beta=1.4(0.9-2.2) \mathrm{Gy}$. Int J Radiat Oncol Biol Phys. 2012;82(1):e17-24

6. Kim Y-J, Cho KH, Pyo HR, et al. A phase II study of hypofractionated proton therapy for prostate cancer. Acta Oncol. 2013;52(3):477-85.

7. Slater JD, Rossi CJ, Yonemoto LT, et al. Proton therapy for prostate cancer: the initial Loma Linda University experience. Int J Radiat Oncol Biol Phys. 2004;59(2):348-52. 
8. Perez CA, Michalski J, Mansur D, et al. Impact of elapsed treatment time on outcome of external-beam radiation therapy for localized carcinoma of the prostate. Cancer J. 2004;10(6):349-56.

9. Yoon $\mathrm{M}$, Kim D, Shin DH, et al. Inter- and intrafractional movement-induced dose reduction of prostate target volume in proton beam treatment. Int J Radiat Oncol Biol Phys. 2008;71(4):1091-102.

10. Simon R, Wittes RE, Ellenberg SS. Randomized phase II clinical trials. Cancer Treat Rep. 1985;69(12):1375-81.

11. Williams SG, Taylor JMG, Liu N, et al. Use of individual fraction size data from 3756 patients to directly determine the alpha/beta ratio of prostate cancer. Int J Radiat Oncol Biol Phys. 2007;68(1):24-33.

12. Nahum AE, Movsas B, Horwitz EM, et al. Incorporating clinical measurements of hypoxia into tumor local control modeling of prostate cancer: implications for the alpha/beta ratio. Int J Radiat Oncol Biol Phys. 2003;57(2):391-401

13. Pollack A, Walker G, Horwitz EM, et al. Randomized trial of hypofractionated external-beam radiotherapy for prostate cancer. J Clin Oncol. 2013;31(31): 3860-8.

14. Lee WR, Dignam JJ, Amin MB, et al. Randomized phase III noninferiority study comparing two radiotherapy fractionation schedules in patients with low-risk prostate Cancer. J Clin Oncol. 2016;34(20):2325-32.

15. Incrocci L, Wortel RC, Alemayehu WG, et al. Hypofractionated versus conventionally fractionated radiotherapy for patients with localised prostate cancer (HYPRO): final efficacy results from a randomised, multicentre, open-label, phase 3 trial. Lancet Oncol. 2016;17(8):1061-9.

16. Dearnaley D, Syndikus I, Mossop H, et al. Conventional versus hypofractionated high-dose intensity-modulated radiotherapy for prostate cancer: 5-year outcomes of the randomised, non-inferiority, phase $3 \mathrm{CHHiP}$ trial. Lancet Oncol. 2016;17(8):1047-60.

17. Catton CN, Lukka H, Gu C-S, et al. Randomized trial of a Hypofractionated radiation regimen for the treatment of localized prostate Cancer. J Clin Oncol. 2017:35(17):1884-90.

18. Loblaw A, Cheung P, D'Alimonte L, et al. Prostate stereotactic ablative body radiotherapy using a standard linear accelerator: toxicity, biochemical, and pathological outcomes. Radiother Oncol. 2013;107(2): 153-8.

19. King CR, Freeman D, Kaplan I, et al. Stereotactic body radiotherapy for localized prostate cancer: pooled analysis from a multi-institutional consortium of prospective phase II trials. Radiother Oncol. 2013;109(2): 217-21.

20. King CR, Brooks JD, Gill H, et al. Long-term outcomes from a prospective trial of stereotactic body radiotherapy for low-risk prostate cancer. Int J Radiat Oncol Biol Phys. 2012;82(2):877-82

21. Kim DWN, Cho LC, Straka C, et al. Predictors of rectal tolerance observed in a dose-escalated phase 1-2 trial of stereotactic body radiation therapy for prostate cancer. Int J Radiat Oncol Biol Phys. 2014; 89(3):509-17.

22. Katz AJ, Kang J. Quality of life and toxicity after SBRT for organ-confined prostate Cancer, a 7-year study. Front Oncol. 2014;4:301.

23. Gao M, Mayr NA, Huang Z, et al. When tumor repopulation starts? The onset time of prostate cancer during radiation therapy. Acta Oncol. 2010; 49(8):1269-75.

24. Lai PP, Pilepich MV, Krall JM, et al. The effect of overall treatment time on the outcome of definitive radiotherapy for localized prostate carcinoma: the radiation therapy oncology group 75-06 and 77-06 experience. Int J Radiat Oncol Biol Phys. 1991;21(4):925-33.

25. Amdur RJ, Parsons JT, Fitzgerald LT, et al. The effect of overall treatment time on local control in patients with adenocarcinoma of the prostate treated with radiation therapy. Int J Radiat Oncol Biol Phys. 1990;19(6):1377-82.

26. Thames HD, Kuban D, Levy LB, et al. The role of overall treatment time in the outcome of radiotherapy of prostate cancer: an analysis of biochemical failure in 4839 men treated between 1987 and 1995. Radiother Oncol. 2010; 96(1):6-12.

27. Kupelian PA, Reddy CA, Klein EA, et al. Short-course intensity-modulated radiotherapy (70 GY at $2.5 \mathrm{GY}$ per fraction) for localized prostate cancer: preliminary results on late toxicity and quality of life. Int J Radiat Oncol Biol Phys. 2001;51(4):988-93.
28. D'Ambrosio DJ, Li T, Horwitz EM, et al. Does treatment duration affect outcome after radiotherapy for prostate cancer? Int J Radiat Oncol Biol Phys. 2008;72(5):1402-7.

29. Morgan SC, Hoffman K, Loblaw DA, et al. Hypofractionated radiation therapy for localized prostate Cancer: executive summary of an ASTRO, ASCO, and AUA evidence-based guideline. Pract Radiat Oncol. 2018;8(6): 354-60.

Ready to submit your research? Choose BMC and benefit from:

- fast, convenient online submission

- thorough peer review by experienced researchers in your field

- rapid publication on acceptance

- support for research data, including large and complex data types

- gold Open Access which fosters wider collaboration and increased citations

- maximum visibility for your research: over $100 \mathrm{M}$ website views per year

At BMC, research is always in progress.

Learn more biomedcentral.com/submissions 